\title{
A Review for Physician Assistants and Nurse Practitioners on the Considerations for Diagnosing and Treating Psoriatic Arthritis
}

Antonio Giannelli

Received: September 24, 2018 / Published online: December 20, 2018

(C) The Author(s) 2018

\section{ABSTRACT}

Psoriatic arthritis (PsA) is a clinically heterogeneous form of progressive inflammatory arthritis that affects up to $30 \%$ of patients with psoriasis. The rapid rate of progression associated with PsA makes early-disease diagnosis and treatment crucial to patients' quality of life and long-term health. With the aim of providing clinical guidance to physician assistants and nurse practitioners, this article gives an overview of the different PsA clinical domains, including peripheral arthritis, axial disease, enthesitis, dactylitis, skin disease, and nail dystrophy, which should be considered as part of diagnosis and treatment strategies. The efficacy of different therapies across these PsA domains is reviewed within the context of current PsA treatment guidelines while considering more recent data on newly approved therapies for PsA.

Funding: Novartis Pharmaceuticals Corp., East Hanover, NJ, USA.

Enhanced digital features To view enhanced digital features for this article go to https://doi.org/10.6084/ m9.figshare.7364234.

A. Giannelli $(\bowtie)$

Great Lakes Center of Rheumatology, Lansing,

MI, USA

e-mail: gnle852@gmail.com
Keywords: Comorbidities; Diagnosis; Nurse practitioner; Physician assistant; Psoriasis; Psoriatic arthritis

\section{INTRODUCTION}

Psoriatic arthritis (PsA) is a form of progressive inflammatory arthritis that is often associated with psoriasis. The prevalence of PsA in the United States is $0.16 \%$, and PsA has been reported to affect up to $30 \%$ of patients suffering from psoriasis $[1,2]$. Both physician assistants and nurse practitioners play a critical role in the early identification and diagnosis of PsA, helping to ensure that patients receive proper treatment to improve their quality of life (QoL), mostly pain and activities of daily living and long-term health.

Although it can affect patients at any age, PsA is typically diagnosed in patients who are 30-50 years old [3]. Frequently, PsA develops within 10 years after the appearance of psoriasis. Nearly $85 \%$ of patients develop psoriasis before PsA; however, $5-10 \%$ of patients display signs of PsA concomitantly with psoriasis, and PsA precedes psoriasis in $5-10 \%$ of patients $[4,5]$.

While the disease can range from mild and monoarthritic to polyarthritic, the rapid rate of progression associated with PsA makes early diagnosis and treatment imperative to positive long-term health outcomes [3]. Within 2 years of disease onset, $47 \%$ of patients have at least one joint erosion, and more than half of 
patients followed for 10 years or more have at least five deformed joints [5]. An estimated 20\% of all patients receiving a PsA diagnosis will eventually develop a disabling form of the disease [5].

To achieve minimal disease activity and improve QoL, patients need to be treated aggressively [6]. In a recent study, the disease burden (health impact in terms of disease activity and patient-reported outcomes) of PsA was shown to be similar to that of rheumatoid arthritis and axial spondyloarthritis [7]. A separate study revealed that patients with psoriasis and PsA have a poorer QoL compared with patients with only psoriasis, as demonstrated by lower scores on the 36-item Short Form Health Survey (SF-36) and the Health Assessment Questionnaire (HAQ; 42.2 vs. 49.7, respectively) [8].

PsA can be challenging to differentiate from other forms of autoimmune arthritis due to its heterogeneous clinical presentation and unpredictable manifestation across six different domains, including peripheral arthritis, axial disease, enthesitis, dactylitis, skin disease, and nail dystrophy. Additionally, the most common domain of inflammatory peripheral arthritis can display symptoms that are seemingly related to rheumatoid arthritis or osteoarthritis. This article will discuss identification of PsA symptoms across different clinical domains, as well as conventional and biologic treatments options for PsA.

This review is based on previously conducted studies and does not contain any studies with human participants or animals performed by the author.

\section{DIAGNOSING PSA: A CAREFUL LOOK AT PATIENT HISTORY AND IDENTIFICATION OF SYMPTOMS}

More than a decade ago, the ClASsification criteria for Psoriatic ARthritis (CASPAR) Study Group developed a set of criteria to standardize classification of patients with PsA for research purposes, which are presented in Table 1. Using
Table 1 CASPAR criteria for classification of PsA

To meet CASPAR criteria, a patient must have inflammatory articular disease with $\geq 3$ points from the categories below [9]

\begin{tabular}{ll}
\hline CASPAR criteria & Points \\
\hline Patient has psoriasis & 2
\end{tabular}

Patient has psoriasis 2

or

Patient does not have psoriasis, but has a personal 1 history of psoriasis

or

Patient does not have psoriasis or a history of 1 psoriasis, but has a family history of psoriasis

Patient has dactylitis or a history of dactylitis 1 recorded by a rheumatologist

Presence of juxta-articular new bone formation 1

Patient is negative for the rheumatoid factor 1

Patient has psoriatic nail dystrophy 1

CASPAR ClASsification criteria for Psoriatic ARthritis, Ps $A$ psoriatic arthritis

these criteria, patients are scored based on the presence or absence of current psoriasis or personal or family history of psoriasis, nail dystrophy; negative blood test for rheumatoid factor, current or previous dactylitis, and radiographic evidence of juxta-articular new bone formation. While these criteria were not developed specifically for use in the differential diagnosis of PsA, many clinicians find it useful to consider these criteria when evaluating patients with suspected PsA $[9,10]$.

\section{Patient History and Family Background}

Given the importance of personal or family history of psoriasis in the CASPAR criteria $[9,10]$, proper records indicating a history of psoriasis are very useful for distinguishing between PsA and other forms of inflammatory arthritis. Specifically, up to $30 \%$ of patients presenting with psoriasis are also affected with PsA [1]. There is also a strong genetic basis for the development of PsA, with significant 
familial aggregation predominantly associated with human leukocyte antigen alleles within the major histocompatibility complex [11]. Due to genetic associations, first-degree relatives of patients with PsA are 49 times more likely to develop PsA than the general population [12]. A patient's susceptibility to PsA (realized by either a personal or family history of psoriasis, or a family history of PsA or other autoimmune disorders) is, therefore, valuable in making an informed diagnosis.

Patient history of failed arthritis treatment, such as nonsteroidal anti-inflammatory drugs (NSAIDs) and acetaminophen, or the presence of arthritis in the absence of trauma should also be considered for diagnosis. For example, degenerative joint disease (osteoarthritis) is often caused by the frequent use of, or injury to, a particular joint. PsA can also be triggered by trauma when an individual is genetically predisposed to psoriasis, but trauma itself is not a hallmark of the disease [13]. Therefore, patients who develop arthritic symptoms without a history of trauma should be carefully examined for other symptoms of PsA.

\section{Key Domains to Consider in PsA Diagnosis}

PsA manifestations are divided into six different domains: peripheral arthritis, axial disease, enthesitis, dactylitis, skin disease, and nail dystrophy [14]. Although patients with PsA may not present with all disease characteristics, it is advantageous to identify disease manifestations that are included in CASPAR criteria and that are important for early detection, such as patient or family history of psoriasis and the presence of dactylitis, nail dystrophy, and radiographic bone changes [15]. Questions that patients can be asked to help identify symptoms of PsA and evaluate response to treatment are provided in Table 2 .

\section{Peripheral Arthritis}

An estimated $95 \%$ of patients with PsA experience inflammation, pain, and/or tenderness in peripheral joints of the hands and/or feet [3]. Affected joints may also display purplish discoloration [16]. While all joints of a digit can be affected, swelling of the distal interphalangeal joints is the most common presentation. Polyarticular patterns of involvement are more common than oligoarticular patterns [3]. Roughly $60 \%$ of patients with peripheral arthritis have symmetric, polyarticular $(>4)$ joint involvement, usually in the hands, feet, and larger weight-bearing joints [17]. Asymmetric oligoarthritis is more common in men and often involves the distal interphalangeal joints, larger joints, and feet [17]. About 5\% of patients with peripheral arthritis develop a severe, destructive form of PsA known as arthritis mutilans, which is associated with telescoping digits, bone destruction and deformity, and profound functional disability [18].

\section{Axial Disease}

Isolated axial joint involvement affects roughly $5 \%$ of patients [3]. However, involvement is a common secondary feature to peripheral arthritis in up to $50 \%$ of patients with PsA. Axial PsA typically presents as asymmetric sacroiliitis or spondylitis. Axial PsA can cause symptoms of morning stiffness and/or immobility; however, axial disease can be asymptomatic in some patients [3]. On physical examination, lateral spinal flexion, cervical rotation, and chest expansion is often restricted in patients with axial disease. Limitations in spinal mobility correlate with radiographic disease progression [19].

\section{Enthesitis}

Enthesitis, defined as inflammation adjacent to joints at tendon, ligament, or joint-capsule insertions, is present in $60-80 \%$ of patients with PsA [20]. Body areas commonly affected by enthesitis in patients with PsA include insertion sites of the plantar fascia and Achilles tendons, as well as ligamentous attachments to the spine, pelvis, and ribs [3]. Enthesitis is more common in lower than in upper extremities, and generally only one or two body sites are simultaneously affected [21, 22]. Symptoms of enthesitis can include soreness or pain at entheses, along with redness and swelling at insertion sites. Risk factors for developing enthesitis among patients with PsA include more actively inflamed joints, higher body mass index, and younger age [21]. 
Table 2 Questions to identify symptoms and evaluate response to treatment by PsA domain

\begin{tabular}{ll}
\hline PsA domain & Identification questions \\
\hline Peripheral arthritis & Do you have trouble in performing daily tasks, such as opening a jar? \\
Axial disease & Do you wake up at night because of low back pain? \\
Enthesitis & Have you ever experienced pain in your heel, knee, or elbow? \\
Dactylitis & Have you ever noticed pain and complete swelling of a single finger or toe? \\
Skin disease & Have you ever had red, itchy, and scaly patches on your skin? \\
Nail dystrophy & Do your fingernails or toenails have holes or pits? \\
\hline PsA domain & Treatment response questions \\
\hline Peripheral arthritis & Have you noticed reduced pain or swelling in your wrists or finger joints? \\
Axial disease & Are you now able to sleep through the night? \\
Enthesitis & Has your ability to climb stairs improved (due to involvement of Achilles tendon)? \\
Dactylitis & Have you noticed a reduction in swelling of the enlarged finger/toe? \\
Skin disease & Has there been improvement to areas of your skin affected by psoriasis? \\
Nail dystrophy & Has the appearance of your fingernails/toenails improved? \\
\hline
\end{tabular}

Ps $A$ psoriatic arthritis

Patients with enthesitis generally have poorer prognosis than patients without this PsA manifestation. Additionally, enthesitis significantly reduces patients' QoL, functional status (due to chronic pain and altered gait, for example) and sleep quality [23].

\section{Dactylitis}

Dactylitis, or "sausage digits," is a common feature of PsA that usually occurs asymmetrically and results in swelling of an entire digit $[16,24]$. Such digits can be identified by swelling and pain along the flexor tendons with limited ranges of motion [25]. When dactylitis affects fingers, swelling can extend to the palm, ulnar bursa, or radial bursa $[26,27]$. Dactylitis affects roughly half of all patients with PsA, and is more commonly observed in toes than fingers and on the right versus the left side [19, 28, 29]. Acute dactylitis presents as swollen, hot, erythemic, painful digits; in chronic cases, swelling is present without inflammation [19, 28]. Dactylitis is typically the first clinical sign of PsA; it may be months or years before other manifestations develop [29]. Often dactylitis recurs in the same digit several times over a patient's lifetime, and digits affected by dactylitis are significantly more likely to have erosive joint damage than non-affected digits. Interestingly, dactylitis has been shown to be an independent risk factor for cardiovascular morbidity in patients with PsA [29].

\section{Skin Disease}

Psoriasis, characterized by skin erythema, thickening, and scaling, precedes development of PsA in about $70 \%$ of patients and develops simultaneously with PsA in about $15 \%$ of patients $[19,30]$. Almost all patients with PsA will have symptoms of psoriasis at some point in their disease course [28]. Development of psoriatic lesions on the scalp and in intergluteal or perianal regions is associated with increased risk of PsA [30]. For example, in a populationbased cohort study, the risk of developing PsA was almost four times higher in patients with scalp psoriasis and was more than doubled in patients with intergluteal/perianal lesions compared with patients without these psoriasis features [31]. 


\section{Nail Dystrophy}

Nail lesions are particularly important in diagnosing PsA because they occur in $66 \%$ of patients with PsA [32]. Signs of disease in the nail matrix include pitting, leukonychia (i.e., white discoloration), nail plate crumbling, red patches on the lunula, and onychorrhexis (i.e., nail ridging). When the nail bed is affected, oil spots, onycholysis, subungual hyperkeratosis, and splinter hemorrhages are the most commonly observed nail changes [32]. Additionally, when the tip of the nail becomes inflamed, the nail plate can become detached [32]. Nail changes in PsA are thought to result from progression of entheseal inflammation in the distal interphalangeal extensor tendon to nail [33].

\section{Differentiating PsA from Other Arthropathies}

The heterogeneous presentation of PsA requires that practitioners evaluate patients across multiple domains to differentiate PsA from other conditions, such as rheumatoid arthritis, ankylosing spondylitis (AS), and osteoarthritis. PsA, much like other arthritides, leads to stiffness and a limited range of motion in affected joints, including large joints-especially those of the lower extremities, distal joints of the fingers and toes, the back, and sacroiliac joints. Inflammatory back pain that worsens during inactivity and morning back stiffness lasting for longer than $1 \mathrm{~h}$ differentiates PsA from osteoarthritis [16]. Inflammation of the sacroiliac joint occurs in roughly $50 \%$ of patients with PsA, but is virtually absent in those with rheumatoid arthritis or osteoarthritis [34]. Asymmetric involvement of sacroiliac joints is indicative of PsA and can help physician assistants and nurse practitioners differentiate PsA from AS [34]. Patients with PsA are also much more likely to have peripheral distribution of arthritis (96\%) compared with patients presenting with AS (25\%) [34].

Symptoms that can distinguish PsA from rheumatoid arthritis and osteoarthritis include plantar fasciitis, Achilles tendon pain, and general heel pain, which can all be signs of enthesitis $[3,12]$. The pattern of disease involvement in peripheral joints can help differentiate between PsA and rheumatoid arthritis. Affected joints usually occur symmetrically in patients with rheumatoid arthritis, whereas PsA often affects the distal interphalangeal and proximal interphalangeal joints, and sometimes all joints on 1 digit, leading to a ray pattern of joint involvement [16]. Dactylitis and enthesitis are hallmark features of PsA that are uncommon in other types of arthritis; thus, the presence of these manifestations can often be used to exclude a diagnosis of rheumatoid arthritis, osteoarthritis, and reactive arthritis $[19,28]$. Lastly, physical examinations and patient-reported outcomes questionnaires, such as SF-36, HAQ, and Routine Assessment of Patient Index Data 3, are important tools for detection of PsA signs and symptoms (Table 3) $[16,35,36]$, and can be critical for identifying back pain, morning stiffness, and undiagnosed psoriatic skin lesions, nail dystrophy, and dactylitis, all of which are indicative of PsA versus rheumatoid arthritis or osteoarthritis [12]. Figure 1a provides an overview of key body areas that should be included in physical examinations, and Fig. 1b gives a visual example of the hand of a patient showing signs of psoriasis, dactylitis, and peripheral arthritis.

\section{TREATMENTS FOR PsA}

Once PsA has been diagnosed, treatment is necessary to improve the patient's QoL (joint pain and swelling, physical activity, and quality of sleep if caused by joint pain) and prevent future bone remodeling (erosion and formation) [37-39]. In 2016, the Group for Research and Assessment of Psoriasis and Psoriatic Arthritis (GRAPPA) and the European League Against Rheumatism (EULAR) both issued updated treatment recommendations for PsA $[14,40]$. Given the breadth of available treatments for PsA and the significant heterogeneity in disease presentation, current guidelines provide treatment recommendations specific to each PsA domain (Fig. 2) [14]. Available treatments often vary in consistency and response across PsA domains. Table 4 summarizes differences in efficacy results from clinical trials of biologics and small-molecule inhibitors for the 
Table 3 Physical examination and questionnaires to detect PsA

\begin{tabular}{ll}
\hline Accompanying symptoms & Assessment \\
\hline Reduced mobility, reduced daily function & SF-36/HAQ/RAPID3 \\
Back pain, morning stiffness & Stiffness $>45 \mathrm{~min}$, asymmetric tenderness or swelling of sacroiliac joint \\
Foot, knee, and elbow pain & $\begin{array}{l}\text { Joint tenderness, joint swelling, and reduced range of motion on physical } \\
\text { examination }\end{array}$ \\
$\begin{array}{l}\text { Undiagnosed psoriatic skin lesions, pitted } \\
\text { nails, and dactylitis }\end{array}$ & $\begin{array}{c}\text { Observance of dry skin patches (especially on elbows and knees), swollen } \\
\text { finger }(\mathrm{s}) / \text { toe }(\mathrm{s}) \text {, or nail pits (even one) }\end{array}$ \\
\hline
\end{tabular}

$H A Q$ Health Assessment Questionnaire, Ps psoriatic arthritis, RAPID3 Routine Assessment of Patient Index Data 3, SF36 36-Item Short Form Health Survey

specific domains of enthesitis and dactylitis; however, because there is no consensus on the best tools for measuring enthesitis and dactylitis in clinical trials, it is not possible to compare many of the results across trials of different targeted therapies. Table 5 shows nail dystrophy efficacy results from clinical trials of targeted therapies in psoriasis and PsA, and Fig. 3 shows results for peripheral arthritis and psoriatic skin disease domains. Considering all differences across therapies, choice of treatment should be optimized to target the PsA domain(s) that are considered to be most severe by the individual patient and healthcare practitioner. Treatment goals should focus on maximizing patients' long-term health-related QoL by preventing structural damage, controlling symptoms, and improving patients' daily functioning $[14,40]$.

\section{Conventional Non-Biologic Therapies}

In the early stages of PsA, intra-articular or intra-muscular corticosteroid injections can be given to help mitigate immediate pain and swelling, and clinical benefits have been observed in patients with persistent monoarthritis and oligoarthritis [20]. NSAIDs can be used as steroid-sparing agents to alleviate musculoskeletal pain and stiffness in patients with peripheral arthritis, axial disease, enthesitis, and/or dactylitis [40-42]. However, corticosteroids and NSAIDs do not prevent PsA progression, so more aggressive therapies are needed in patients with erosive disease $[1,12]$. Additionally, both corticosteroids and NSAIDs are associated with increased risks of adverse events and may be contraindicated for some patients $[14,40]$. For patients with skin disease, topical therapies (e.g., keratolytics, steroids, vitamin D analogues, emollients, and calcineurin inhibitors), followed by phototherapy are recommended non-biologic treatment options that can be effective for mild psoriasis [14]. Co-management with a dermatologist should be considered.

Conventional synthetic disease-modifying anti-rheumatic drugs (csDMARDs), such as sulfasalazine and methotrexate, are steroidsparing agents that are recommended for use after failure of NSAIDs and to treat locally active peripheral arthritis, psoriasis, and nail dystrophy [40-42]. Methotrexate is usually recommended as the first-choice csDMARD for most patients, especially those with skin involvement; however, robust data on the efficacy of methotrexate are lacking, and many patients cannot tolerate methotrexate or have contraindications $[1,12]$. Notably, csDMARDs can take several weeks to become effective and therefore, must be started early in disease diagnosis to maximize patient benefits [40].

\section{Biologics and Targeted Small-Molecule Inhibitors}

\section{Tumor Necrosis Factor Inhibitors}

Tumor necrosis factor (TNF) is a pro-inflammatory cytokine that is overexpressed in the synovium of patients with inflammatory arthritis, promoting synoviocyte hyperproliferation, 


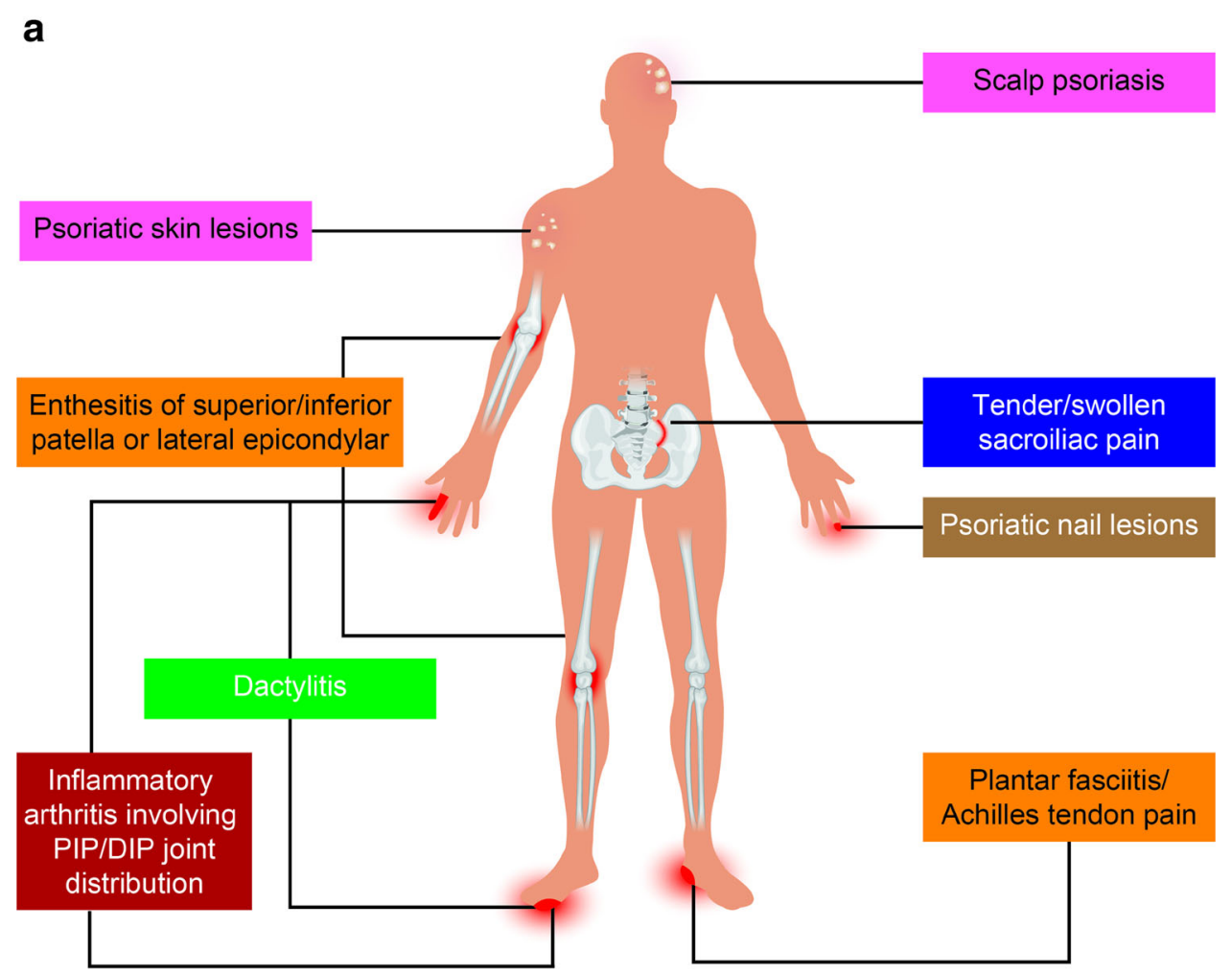

\begin{tabular}{|ll|}
\hline 6 GRAPPA Domains of PsA & \\
$\square$ Peripheral Arthritis & Dactylitis \\
Axial Disease & Skin \\
Enthesitis & Nails \\
\hline
\end{tabular}

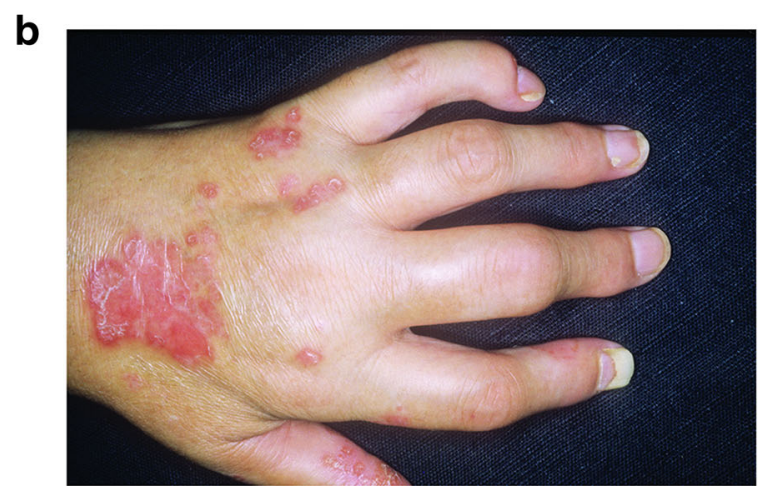

Fig. 1 Clinical features of PsA. a Areas of the body affected by the different clinical domains of PsA. DIP distal interphalangeal, PIP proximal interphalangeal, GRAPPA Group for Research and Assessment of Psoriasis and Psoriatic Arthritis, $P s A$ psoriatic arthritis. b The hand of a patient with PsA [76]. Psoriatic lesions and the involvement of peripheral joints are indicative of PsA. Reproduced with permission from: dermnet.com 76 


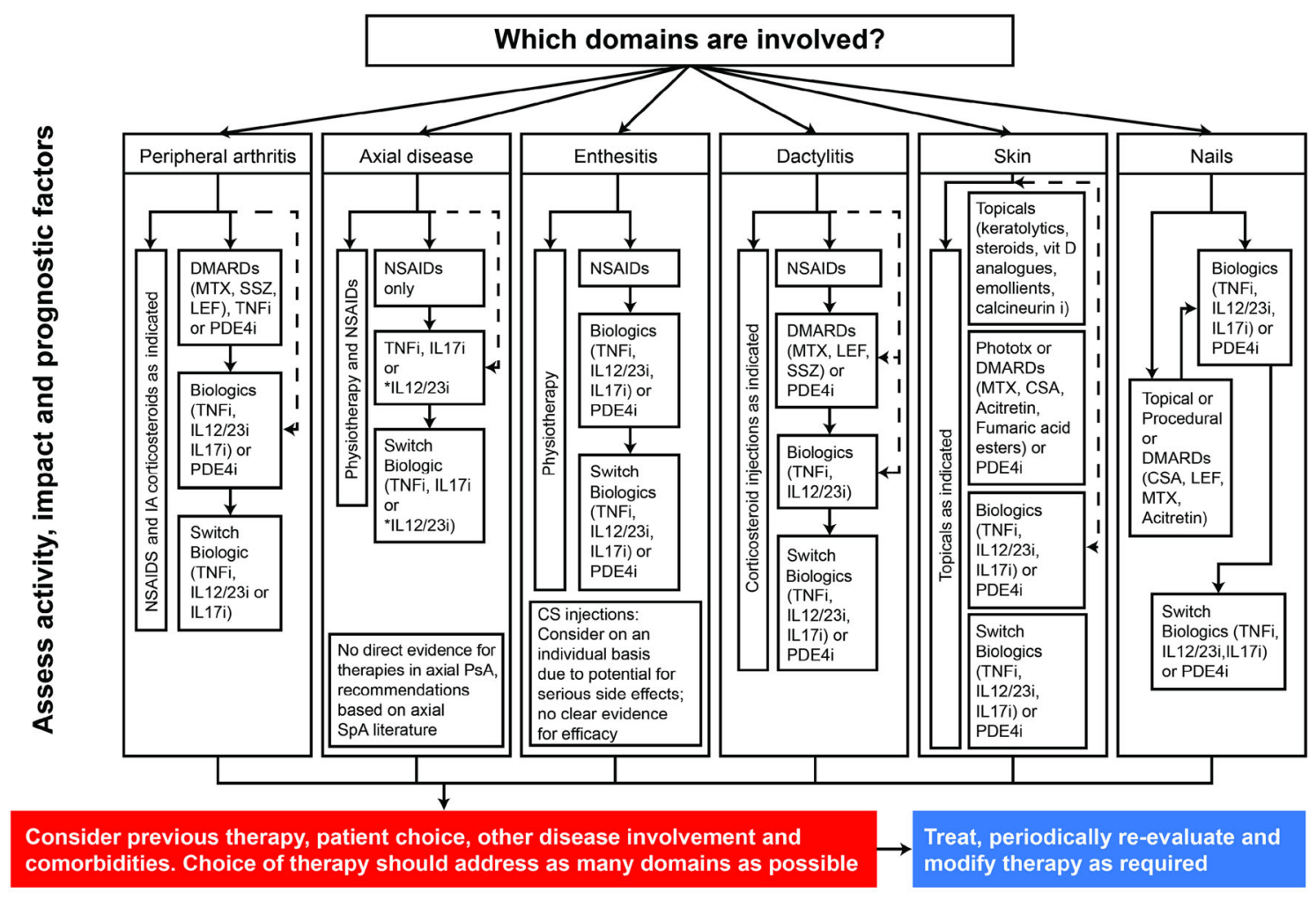

$\longrightarrow$ Standard Therapeutic Route

Fig. 2 GRAPPA treatment schema for active PsA* [14]. Reproduced with permission from: Coates LC, Kavanaugh A, Mease PJ, et al. Group for Research and Assessment of Psoriasis and Psoriatic Arthritis 2015 treatment recommendations for psoriatic arthritis. Arthritis Rheumatol.

macrophage infiltration, and synovial thickening [43]. Biologic therapies that inhibit TNF have demonstrated efficacy across all six PsA domains and are key components of current PsA treatment guidelines (Fig. 2) [14, 40]. The following TNF inhibitors are approved for the treatment of active PsA: etanercept, adalimumab, infliximab, certolizumab pegol, and golimumab. TNF inhibitors are available in formulations for subcutaneous injection (etanercept, adalimumab, certolizumab pegol, and golimumab) and for intravenous infusion (infliximab and golimumab), giving patients the option to choose their preferred route of administration based on factors such as convenience and whether they have anxiety about self-injection.

TNF inhibitors are currently a cornerstone of biologic treatment recommendations for PsA $-\rightarrow$ Expedited Therapeutic Route

2016;68:1060-71. * Light text identifies conditional recommendations for drugs that do not currently have regulatory approvals or for which recommendations are based on abstract data only

$[14,40]$, largely due to their established history as safe and effective treatments for both rheumatic and psoriatic disease [44]. However, TNF is an upstream modulator of PsA pathogenesis, and targeting this cytokine can have relatively non-specific effects on PsA disease features, such as osteoclastogenesis and synovial inflammation [43]. As such, some patients with PsA fail to respond to TNF inhibitors. Additionally, among individuals who do respond to initial treatment, efficacy can wane over time, resulting in failure to achieve lasting remission [44, 45].

\section{Interleukin-12/23 Inhibitor}

Interleukin (IL)-12 and IL-23 are important cytokines in the pathogenesis of PsA and psoriasis. Upregulation of IL-12 promotes inflammation and activation of natural killer cells, and upregulation of IL-23 stimulates processes 


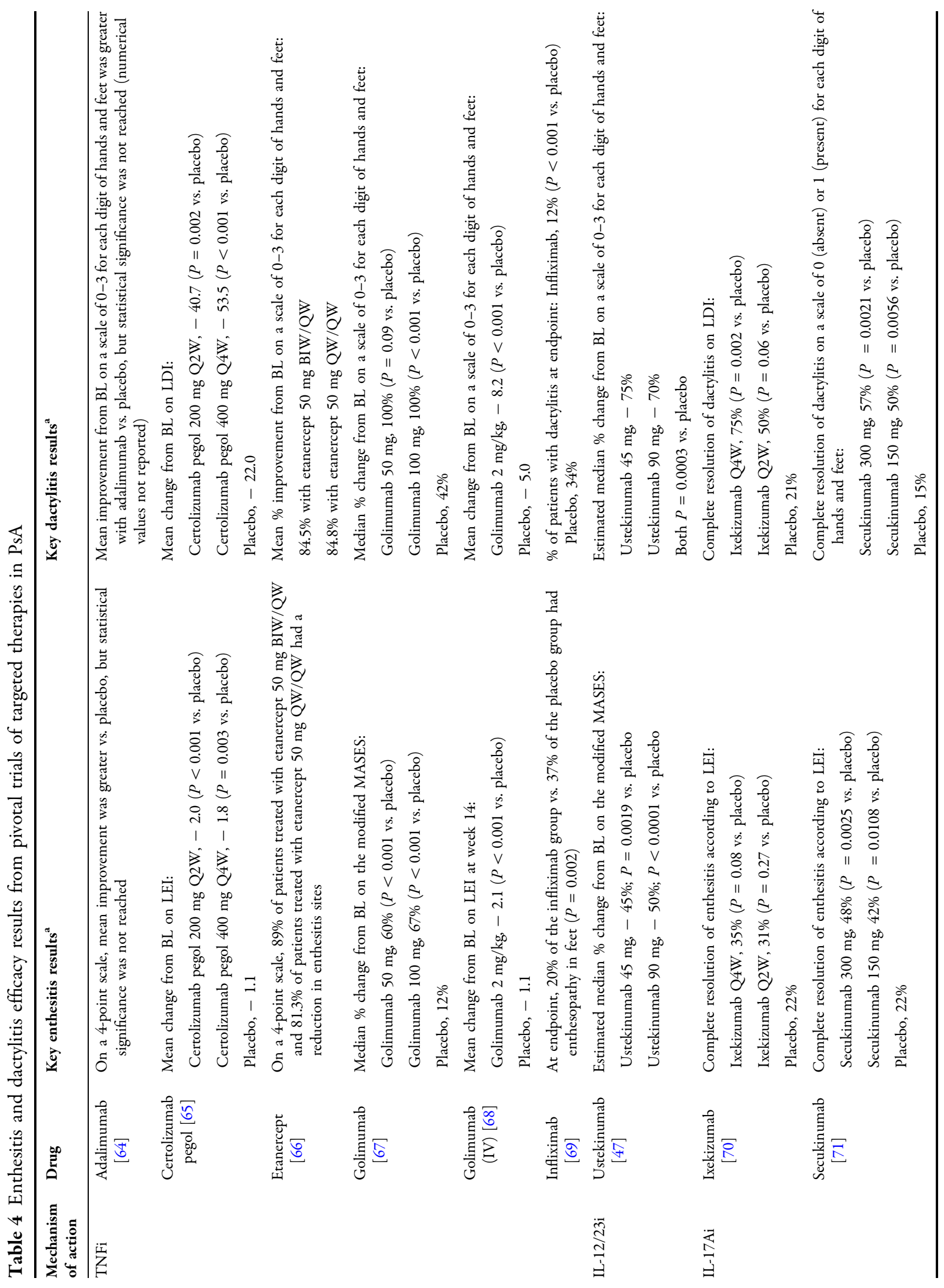




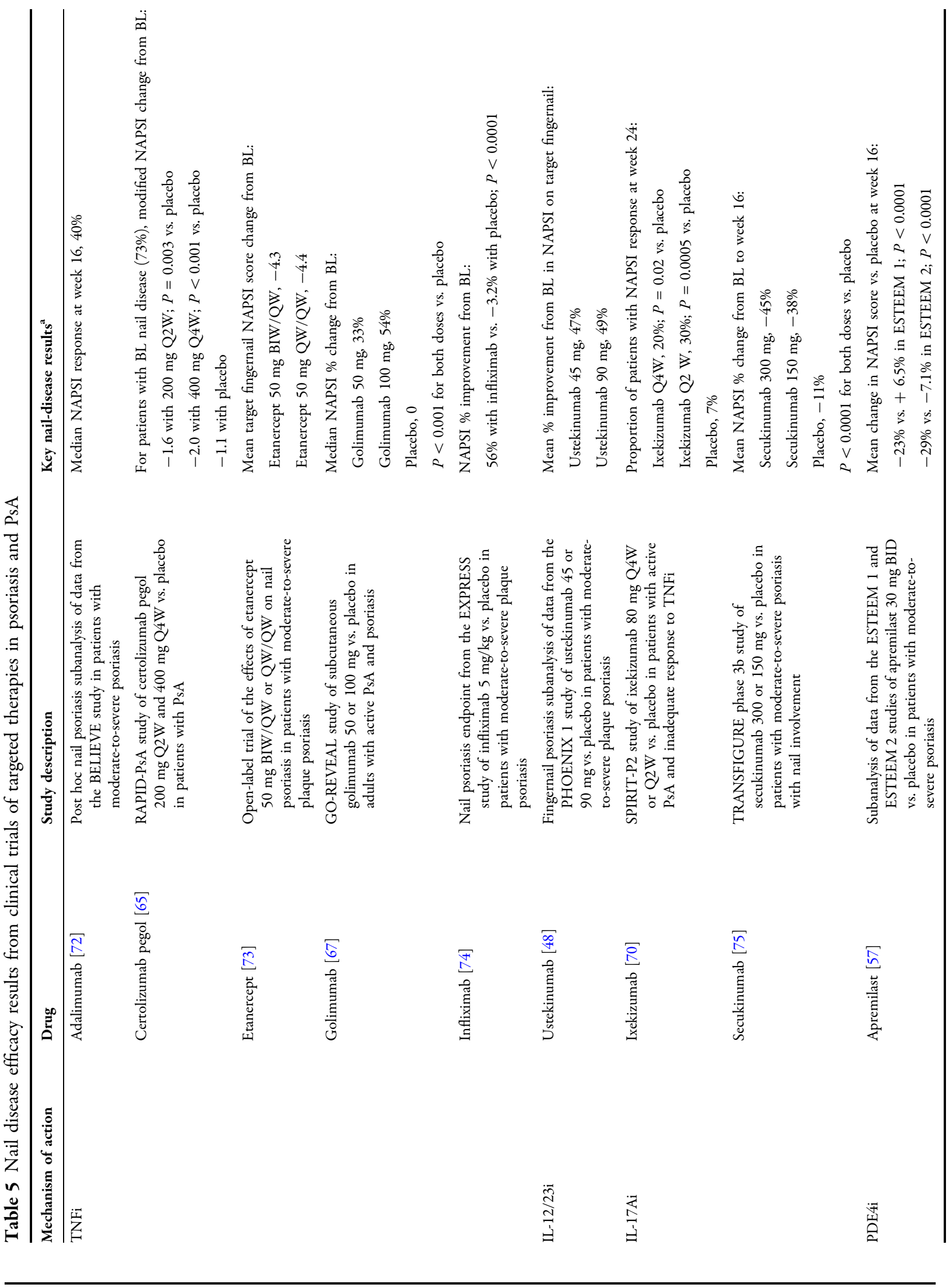




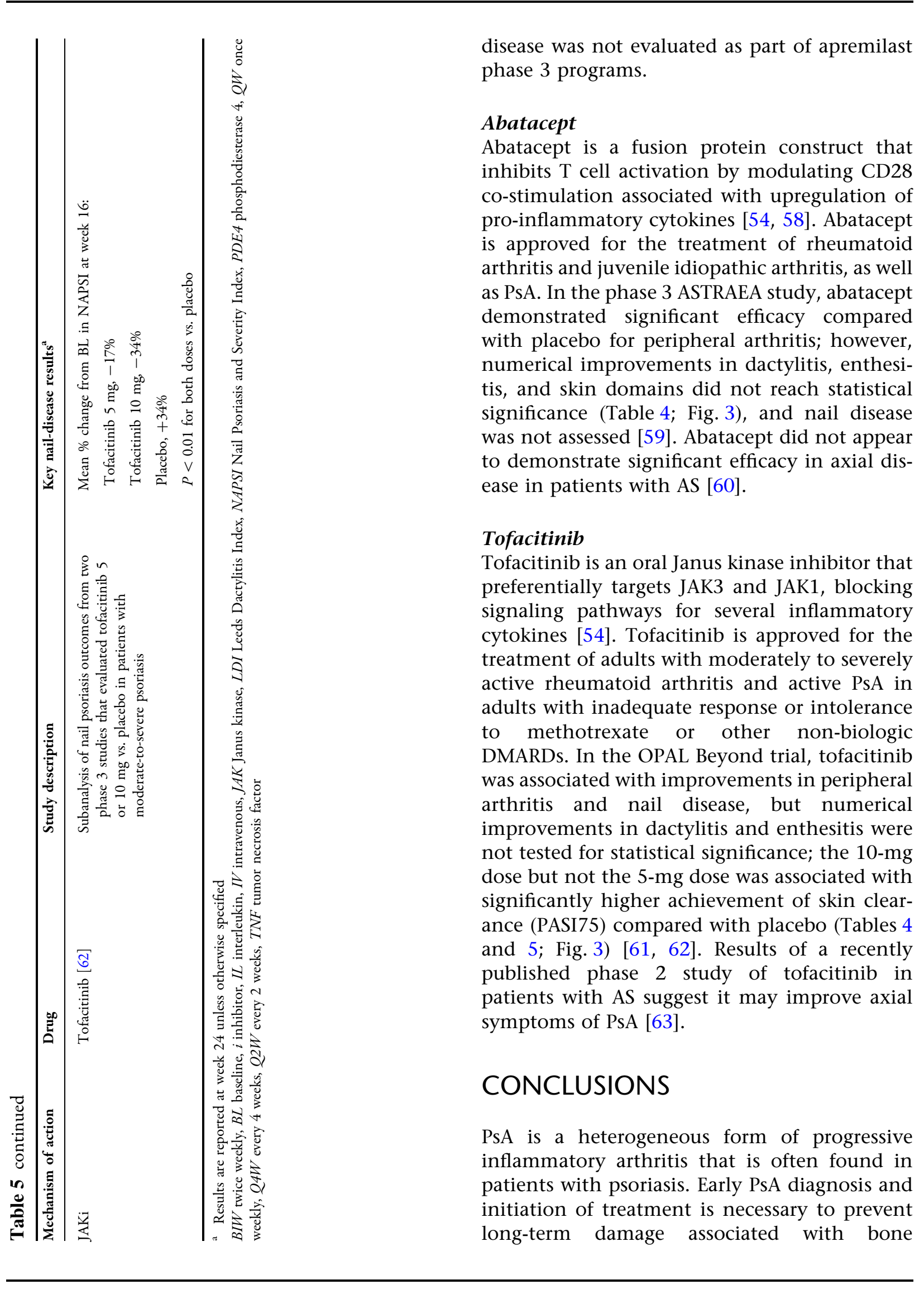



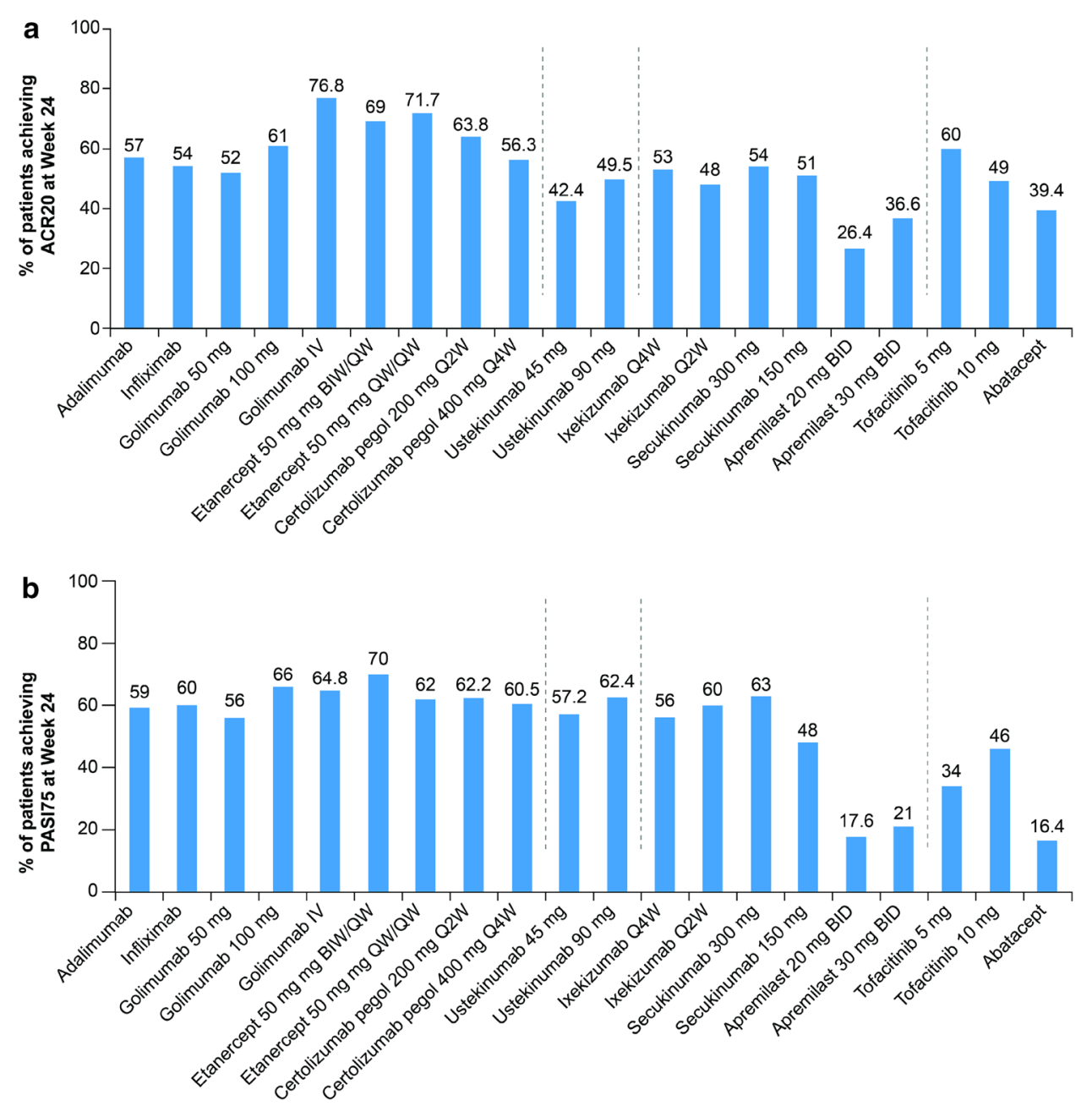

Fig. 3 a ACR20 and b PASI75 response rates reported at week 24 in phase 3 trials of targeted therapies approved for the treatment of active PsA [47, 56, 59, 61, 64-71]. For agents without a dose specified, results are presented for the approved dosage. Figure is for visualization purposes

remodeling and to improve patient QoL. By recognizing each of the PsA clinical domains (peripheral arthritis, axial disease, dactylitis, enthesitis, skin disease, and nail dystrophy) and obtaining information on a patient's personal and family history as well as administering an in-depth physical examination, physician assistants and nurse practitioners can play an important role in the early recognition, diagnosis, and treatment of PsA. Treatment choices should be tailored based on the efficacy profiles of available drugs for each PsA domain to target the clinical manifestation(s) causing the only and should not be used to make direct comparisons of efficacy between therapies. ACR American College of Rheumatology, BID twice daily, $I V$ intravenous, $P A S I$ Psoriasis Area Severity Index, $P s A$ psoriatic arthritis, $Q 4 W$ every 4 weeks, $Q 2 W$ every 2 weeks, $Q W$ once weekly

greatest burden for each patient. Newer therapies may provide effective treatment across multiple PsA clinical domains, offering alternatives to treatments emphasized in the most recent guidelines for PsA management.

\section{ACKNOWLEDGEMENTS}

Funding. Sponsorship for this manuscript and article processing charges were funded by 
Novartis Pharmaceuticals Corp., East Hanover, NJ, USA.

Editorial Assistance. Editorial assistance in the preparation of this manuscript was provided by Dr. Scott Forbes of Oxford PharmaGenesis Inc., Newtown, PA, USA and was funded by Novartis Pharmaceuticals Corporation.

Authorship. The named author meets the international Committee of Medical Journal Editors (ICMJE) criteria for authorship for this manuscript, takes responsibility for the integrity of the work as a whole, and has given final approval to the version to be published.

Disclosures. Antonio Giannelli is independent contractor for Sanofi, Regeneron Lilly, Celgene, Novartis, and Pfizer.

Compliance with Ethics Guidelines. This review is based on previously conducted studies and does not contain any studies with human participants or animals performed by the author.

Data Availability. Data sharing is not applicable to this article as no datasets were generated or analyzed during the current study.

Open Access. This article is distributed under the terms of the Creative Commons Attribution-NonCommercial 4.0 International License (http://creativecommons.org/licenses/ by-nc/4.0/), which permits any noncommercial use, distribution, and reproduction in any medium, provided you give appropriate credit to the original author(s) and the source, provide a link to the Creative Commons license, and indicate if changes were made.

\section{REFERENCES}

1. Gladman DD. Psoriatic arthritis. Dermatol Ther. 2009;22:40-55.

2. Wilson FC, Icen M, Crowson CS, McEvoy MT, Gabriel SE, Kremers HM. Time trends in epidemiology and characteristics of psoriatic arthritis over 3 decades: a population-based study. J Rheumatol. 2009;36:361-7.

3. Gottlieb A, Korman NJ, Gordon KB, et al. Guidelines of care for the management of psoriasis and psoriatic arthritis: section 2. Psoriatic arthritis: overview and guidelines of care for treatment with an emphasis on the biologics. J Am Acad Dermatol. 2008;58:851-64.

4. Catanoso M, Pipitone N, Salvarani C. Epidemiology of psoriatic arthritis. Reumatismo. 2012;64:66-70.

5. Gladman DD, Antoni C, Mease P, Clegg DO, Nash P. Psoriatic arthritis: epidemiology, clinical features, course, and outcome. Ann Rheum Dis. 2005;64 Suppl 2:ii14-7.

6. Coates LC, Helliwell PS. Treat to target in psoriatic arthritis-evidence, target, research agenda. Curr Rheumatol Rep. 2015;17:517.

7. Michelsen B, Fiane R, Diamantopoulos AP, et al. A comparison of disease burden in rheumatoid arthritis, psoriatic arthritis and axial spondyloarthritis. PLoS One. 2015;10:e0123582.

8. Rosen CF, Mussani F, Chandran V, Eder L, Thavaneswaran A, Gladman DD. Patients with psoriatic arthritis have worse quality of life than those with psoriasis alone. Rheumatology (Oxford). 2012;51:571-6.

9. Taylor W, Gladman D, Helliwell P, et al. Classification criteria for psoriatic arthritis: development of new criteria from a large international study. Arthritis Rheum. 2006;54:2665-73.

10. Mease PJ, Armstrong AW. Managing patients with psoriatic disease: the diagnosis and pharmacologic treatment of psoriatic arthritis in patients with psoriasis. Drugs. 2014;74:423-41.

11. O'Rielly DD, Rahman P. Genetics of psoriatic arthritis. Best Pract Res Clin Rheumatol. 2014;28:673-85.

12. de Vlam K, Gottlieb AB, Mease PJ. Current concepts in psoriatic arthritis: pathogenesis and management. Acta Derm Venereol. 2014;94:627-34.

13. Olivieri I, Padula A, D'Angelo S, Scarpa R. Role of trauma in psoriatic arthritis. J Rheumatol. 2008;35:2085-7.

14. Coates LC, Kavanaugh A, Mease PJ, et al. Group for research and assessment of psoriasis and psoriatic arthritis 2015 treatment recommendations for psoriatic arthritis. Arthritis Rheumatol. 2016;68:1060-71.

15. Olivieri I, D'Angelo S, Padula A, Palazzi C. The challenge of early diagnosis of psoriatic arthritis. J Rheumatol. 2008;35:3-5. 
16. Busse K, Liao W. Which psoriasis patients develop psoriatic arthritis? Psoriasis Forum. 2010;16:17-25.

17. Acosta Felquer ML, FitzGerald O. Peripheral joint involvement in psoriatic arthritis patients. Clin Exp Rheumatol. 2015;33:S26-30.

18. Haddad A, Johnson SR, Somaily M, et al. Psoriatic arthritis mutilans: clinical and radiographic criteria: a systematic review. J Rheumatol. 2015;42:1432-8.

19. Gladman DD. Clinical features and diagnostic considerations in psoriatic arthritis. Rheum Dis Clin North Am. 2015;41:569-79.

20. Coates LC, Helliwell PS. Psoriatic arthritis: state of the art review. Clin Med (Lond). 2017;17:65-70.

21. Polachek A, Li S, Chandran V, Gladman DD. Clinical enthesitis in a prospective longitudinal psoriatic arthritis cohort: incidence, prevalence, characteristics, and outcome. Arthritis Care Res (Hoboken). 2017;69:1685-91.

22. Sakkas LI, Alexiou I, Simopoulou T, Vlychou M. Enthesitis in psoriatic arthritis. Semin Arthritis Rheum. 2013;43:325-34.

23. Kaeley GS, Eder L, Aydin SZ, Gutierrez M, Bakewell C. Enthesitis: a hallmark of psoriatic arthritis. Semin Arthritis Rheum. 2018;48:35-43.

24. Mok M. The clinical spectrum and diagnosis of psoriatic arthropathy. Hong Kong Med Diary. 2010;15:5-7.

25. Olivieri I, Padula A, Scarano E, Scarpa R. Dactylitis or "sausage-shaped" digit. J Rheumatol. 2007;34:1217-22.

26. Padula A, Salvarani C, Barozzi L, et al. Dactylitis also involving the synovial sheaths in the palm of the hand: two more cases studied by magnetic resonance imaging. Ann Rheum Dis. 1998;57:61-2.

27. Olivieri I, Scarano E, Padula A, Giasi V. Dactylitis of the thumb extending to the radial bursa. J Rheumatol. 2003;30:1626-7.

28. Ritchlin CT, Colbert RA, Gladman DD. Psoriatic arthritis. N Engl J Med. 2017;376:957-70.

29. Kaeley GS, Eder L, Aydin SZ, Gutierrez M, Bakewell C. Dactylitis: a hallmark of psoriatic arthritis. Semin Arthritis Rheum. 2018;48:35-43.

30. Ruiz DG, Azevedo MN, Santos OL. Psoriatic arthritis: a clinical entity distinct from psoriasis? Rev Bras Reumatol. 2012;52:630-8.

31. Wilson FC, Icen M, Crowson CS, McEvoy MT, Gabriel SE, Kremers HM. Incidence and clinical predictors of psoriatic arthritis in patients with psoriasis: a population-based study. Arthritis Rheum. 2009;61:233-9.

32. Sandre MK, Rohekar S. Psoriatic arthritis and nail changes: exploring the relationship. Semin Arthritis Rheum. 2014;44:162-9.

33. Raposo I, Torres T. Nail psoriasis as a predictor of the development of psoriatic arthritis. Actas Dermosifiliogr. 2015;106:452-7.

34. Gladman DD. Clinical, radiological, and functional assessment in psoriatic arthritis: is it different from other inflammatory joint diseases? Ann Rheum Dis. 2006;65 Suppl 3:iii22-4.

35. Mease PJ, Behrens F, Boehncke WH, et al. Discussion: assessment of psoriatic arthritis. Ann Rheum Dis. 2005;64(Suppl II):ii69-73.

36. Coates LC, Tillett W, Shaddick G, Pincus T, Kavanaugh A, Helliwell PS. Value of the routine assessment of patient index data 3 in patients with psoriatic arthritis: results from a tight-control clinical trial and an observational cohort. Arthritis Care Res (Hoboken). 2018;70:1198-205.

37. Paine A, Ritchlin C. Bone remodeling in psoriasis and psoriatic arthritis: an update. Curr Opin Rheumatol. 2016;28:66-75.

38. Raychaudhuri SK, Saxena A, Raychaudhuri SP. Role of IL-17 in the pathogenesis of psoriatic arthritis and axial spondyloarthritis. Clin Rheumatol. 2015;34:1019-23.

39. Saad AA, Ashcroft DM, Watson $\mathrm{KD}$, et al. Improvements in quality of life and functional status in patients with psoriatic arthritis receiving anti-tumor necrosis factor therapies. Arthritis Care Res (Hoboken). 2010;62:345-53.

40. Gossec L, Smolen JS, Ramiro S, et al. European League Against Rheumatism (EULAR) recommendations for the management of psoriatic arthritis with pharmacological therapies: 2015 update. Ann Rheum Dis. 2016;75:499-510.

41. Gossec L, Smolen JS, Gaujoux-Viala C, et al. European League Against Rheumatism recommendations for the management of psoriatic arthritis with pharmacological therapies. Ann Rheum Dis. $2012 ; 71: 4-12$.

42. Raja Babu KK. Pharmacological interventions for psoriatic arthritis: present and future. Indian J Dermatol Venereol Leprol. 2002;68:187-97.

43. Addimanda O, Possemato N, Caruso A, Pipitone N, Salvarani C. The role of tumor necrosis factor- $\alpha$ blockers in psoriatic disease. Therapeutic options in 
psoriatic arthritis. J Rheumatol Suppl. 2015;93:73-8.

44. Mease P. A short history of biological therapy for psoriatic arthritis. Clin Exp Rheumatol. 2015;33:S104-8.

45. Garrido-Cumbrera M, Hillmann O, Mahapatra R, et al. Improving the management of psoriatic arthritis and axial spondyloarthritis: roundtable discussions with healthcare professionals and patients. Rheumatol Ther. 2017;4:219-31.

46. Marinoni B, Ceribelli A, Massarotti MS, Selmi C. The Th17 axis in psoriatic disease: pathogenetic and therapeutic implications. Auto Immun Highlights. 2014;5:9-19.

47. McInnes IB, Kavanaugh A, Gottlieb AB, et al. Efficacy and safety of ustekinumab in patients with active psoriatic arthritis: 1 year results of the phase 3 , multicentre, double-blind, placebo-controlled PSUMMIT 1 trial. Lancet. 2013;382:780-9.

48. Rich $\mathrm{P}$, Bourcier $\mathrm{M}$, Sofen $\mathrm{H}$, et al. Ustekinumab improves nail disease in patients with moderate-tosevere psoriasis: results from PHOENIX 1. Br J Dermatol. 2014;170:398-407.

49. Kavanaugh A, Ritchlin C, Rahman $\mathrm{P}$, et al. Ustekinumab, an anti-IL-12/23 p40 monoclonal antibody, inhibits radiographic progression in patients with active psoriatic arthritis: results of an integrated analysis of radiographic data from the phase 3, multicentre, randomised, double-blind, placebo-controlled PSUMMIT-1 and PSUMMIT-2 trials. Ann Rheum Dis. 2014;73:1000-6.

50. Ritchlin C, Rahman P, Kavanaugh A, et al. Efficacy and safety of the anti-IL-12/23 p40 monoclonal antibody, ustekinumab, in patients with active psoriatic arthritis despite conventional non-biological and biological anti-tumour necrosis factor therapy: 6-month and 1-year results of the phase 3 , multicentre, double-blind, placebo-controlled, randomised PSUMMIT 2 trial. Ann Rheum Dis. 2014;73:990-9.

51. Cosentyx (secukinumab) [prescribing information]. Novartis, East Hanover. 2018.

52. Baeten D, Sieper J, Braun J, et al. Secukinumab, an interleukin-17A inhibitor, in ankylosing spondylitis. N Engl J Med. 2015;373:2534-48.

53. Braun J, Baraliakos X, Deodhar A, et al. Effect of secukinumab on clinical and radiographic outcomes in ankylosing spondylitis: 2-year results from the randomised phase III MEASURE 1 study. Ann Rheum Dis. 2017;76:1070-7.
54. Kang EJ, Kavanaugh A. Psoriatic arthritis: latest treatments and their place in therapy. Ther Adv Chronic Dis. 2015;6:194-203.

55. Edwards CJ, Blanco FJ, Crowley J, et al. Apremilast, an oral phosphodiesterase 4 inhibitor, in patients with psoriatic arthritis and current skin involvement: a phase III, randomised, controlled trial (PALACE 3). Ann Rheum Dis. 2016;75:1065-73.

56. Kavanaugh A, Mease PJ, Gomez-Reino JJ, et al. Treatment of psoriatic arthritis in a phase 3 randomised, placebo-controlled trial with apremilast, an oral phosphodiesterase 4 inhibitor. Ann Rheum Dis. 2014;73:1020-6.

57. Rich $\mathrm{P}$, Gooderham M, Bachelez H, et al. Apremilast, an oral phosphodiesterase 4 inhibitor, in patients with difficult-to-treat nail and scalp psoriasis: results of 2 phase III randomized, controlled trials (ESTEEM 1 and ESTEEM 2). J Am Acad Dermatol. 2016;74:134-42.

58. Ursini F, Naty S, Russo E, Grembiale RD. Abatacept in psoriatic arthritis: case report and short review. J Pharmacol Pharmacother. 2013;4:S29-32.

59. Mease PJ, Gottlieb AB, van der Heijde D, et al. Efficacy and safety of abatacept, a T-cell modulator, in a randomised, double-blind, placebo-controlled, phase III study in psoriatic arthritis. Ann Rheum Dis. $2017 ; 76: 1550-8$.

60. Song IH, Heldmann F, Rudwaleit M, et al. Treatment of active ankylosing spondylitis with abatacept: an open-label, 24-week pilot study. Ann Rheum Dis. 2011;70:1108-10.

61. Gladman D, Rigby W, Azevedo VF, et al. Tofacitinib for psoriatic arthritis in patients with an inadequate response to TNF inhibitors. $\mathrm{N}$ Engl $\mathrm{J}$ Med. 2017;377:1525-36.

62. Merola JF, Elewski B, Tatulych S, Lan S, Tallman A, Kaur M. Efficacy of tofacitinib for the treatment of nail psoriasis: two 52-week, randomized, controlled phase 3 studies in patients with moderate-to-severe plaque psoriasis. J Am Acad Dermatol. 2017;77(79-87):e1.

63. van der Heijde D, Deodhar A, Wei JC, et al. Tofacitinib in patients with ankylosing spondylitis: a phase II, 16-week, randomised, placebo-controlled, dose-ranging study. Ann Rheum Dis. 2017;76:1340-7.

64. Mease PJ, Gladman DD, Ritchlin CT, et al. Adalimumab for the treatment of patients with moderately to severely active psoriatic arthritis: results of a double-blind, randomized, placebocontrolled trial. Arthritis Rheum. 2005;52:3279-89. 
65. Mease PJ, Fleischmann R, Deodhar AA, et al. Effect of certolizumab pegol on signs and symptoms in patients with psoriatic arthritis: 24 -week results of a phase 3 double-blind randomised placebo-controlled study (RAPID-PsA). Ann Rheum Dis. 2014;73:48-55.

66. Sterry W, Ortonne JP, Kirkham B, et al. Comparison of two etanercept regimens for treatment of psoriasis and psoriatic arthritis: PRESTA randomised double blind multicentre trial. BMJ. 2010;340:c147.

67. Kavanaugh A, McInnes I, Mease P, et al. Golimumab, a new human tumor necrosis factor $\alpha$ antibody, administered every four weeks as a subcutaneous injection in psoriatic arthritis: twentyfour-week efficacy and safety results of a randomized, placebo-controlled study. Arthritis Rheum. 2009;60:976-86.

68. Kavanaugh A, Husni ME, Harrison DD, et al. Safety and efficacy of intravenous golimumab in patients with active psoriatic arthritis: results through week twenty-four of the GO-VIBRANT study. Arthritis Rheumatol. 2017;69:2151-61.

69. Antoni C, Krueger GG, de Vlam K, et al. Infliximab improves signs and symptoms of psoriatic arthritis: results of the IMPACT 2 trial. Ann Rheum Dis. 2005;64:1150-7.

70. Nash P, Kirkham B, Okada M, et al. Ixekizumab for the treatment of patients with active psoriatic arthritis and an inadequate response to tumour necrosis factor inhibitors: results from the 24-week randomised, double-blind, placebo-controlled period of the SPIRIT-P2 phase 3 trial. Lancet. 2017;389:2317-27.

71. McInnes IB, Mease PJ, Kirkham B, et al. Secukinumab, a human anti-interleukin-17A monoclonal antibody, in patients with psoriatic arthritis (FUTURE 2): a randomised, double-blind, placebocontrolled, phase 3 trial. Lancet. 2015;386:1137-46.

72. Thaci D, Unnebrink K, Sundaram M, Sood S, Yamaguchi Y. Adalimumab for the treatment of moderate to severe psoriasis: subanalysis of effects on scalp and nails in the BELIEVE study. J Eur Acad Dermatol Venereol. 2015;29:353-60.

73. Ortonne JP, Paul C, Berardesca E, et al. A 24-week randomized clinical trial investigating the efficacy and safety of two doses of etanercept in nail psoriasis. Br J Dermatol. 2013;168:1080-7.

74. Reich K, Nestle FO, Papp K, et al. Infliximab induction and maintenance therapy for moderateto-severe psoriasis: a phase III, multicentre, doubleblind trial. Lancet. 2005;366:1367-74.

75. Reich K, Arenberger P, Mrowietz U, et al. Secukinumab shows high and sustained efficacy in nail psoriasis: 1.5-year results from the TRANSFIGURE study. In: Presented at the American Academy of Dermatology annual meeting, Orlando, 3-7 Mar 2017.

76. Dermnet. Psoriatic arthritis photo. http://www. dermnet.com/images/Psoriatic-Arthritis/picture/ 7097. Cited 9 Dec 2016. 